\title{
Macrofauna recolonization of subtidal sediments. Experimental studies on defaunated sediment contaminated with crude oil in two Norwegian fjords with unequal eutrophication status. I. Community responses
}

\author{
John Arthur Berge \\ Norwegian Institute for Water Research, PO Box 69 Korsvoll, N-0808 Oslo 8, Norway* \\ and
}

Department of Biology, Section of Marine Zoology and Chemistry, University of Oslo, PO Box 1064, Blindern, N-0316 Oslo 3 , Norway

\begin{abstract}
Experiments were performed by placing oiled and unoiled defaunated sediment in boxes $\left(0.2 \mathrm{~m}^{2}\right)$ on the sea floor in 2 Norwegian fjords, the eutrophicated Oslofjord (4 boxes, April to July 1980) and the non-eutrophicated Raunefjord (12 boxes, February 1981 to March 1982). In the Oslofjord no negative effects of the added oil ( $3920 \mathrm{ppm}$ wet weight sediment) on macrofauna community structure were seen after 3 mo. Thus restoration of the community took less than 3 mo during a spring/summer situation in a soft bottom area with a species composition dominated by opportunistic species (Polydora $\mathrm{spp}$.). In the Raunefjord the effect of the added oil $(4520 \mathrm{ppm})$ was shown in reduced species diversity after $4 \mathrm{mo}$, and altered $\mathrm{k}$-dominance curves, distribution of individuals among species, Hurlbert's rarefaction curves and multidimensional scaling plots. The added oil reduced the mean equilibrium number of species per box from 80 to 55 . The time needed to reach $90 \%$ of this equilibrium was shorter in the oiled boxes ( $259 \mathrm{~d}$ ) than in the control boxes ( $466 \mathrm{~d}$ ). Effects were most severe after 4 mo on the filter-feeders and surface deposit feeders, after 9 and 13 mo on subsurface deposit feeders. Immigration rates were similar $\left(0.27\right.$ species $\mathrm{d}^{-1}$ box $\left.{ }^{-1}\right)$ in both treatments during June to November; however, from November to March the rate was higher in control boxes (0.24) than in oiled boxes (0.17). Mean extinction rates in boxes (species/species $\mathrm{d}^{-1}$ box ${ }^{-1}$ ) were, however, larger in the oiled boxes than in the control boxes during both periods (Oil: 0.0048, 0.0033; Control: 0.0027, 0.0024). For both fjords animals retained on a $250 \mu \mathrm{m}$ sieve generally showed higher densities in the oiled sediment. It is concluded that restoration of the benthic macrofauna after oil contamination of sediment takes longer in a noneutrophicated area than in a eutrophicated area. The reduced density of macrofauna in the oiled boxes in the Raunefjord was caused by toxic response to oil directly, or by secondary effects leading to increased mortality, rather than by reduced settlement. Macrofauna recolonization is easily affected by oil-contamination in a non-eutrophicated area; however separation of oil-specific responses in benthic communities from responses to other disturbances can hardly be demonstrated without relevant controls.
\end{abstract}

\section{INTRODUCTION}

Perturbations of marine sediment may defaunate or disturb patches in soft bottom communities which subsequently are recolonized. This process maintains spatio-temporal mosaics in soft-bottom communities (see Johnson 1972), both in coastal sediments and in

\footnotetext{
- Present address
}

the deep sea (Smith 1986). Recolonization is thus a fundamental structuring process in soft-bottom benthic communities. Perturbations in the benthos may be natural (Dauer \& Simon 1976, Santos \& Simon 1980a, b, Nerini \& Oliver 1983, Santos \& Bloom 1983) or manmade (review by Pearson \& Rosenberg 1978, Bonsdorff 1983), and may vary markedly both in extent (Probert 1984) and character depending on disturbing agent (Thistle 1981). 
The degree, manner and speed of restoration of initial community structure and function after a disturbance (resilience; Westman 1978) is related to the type and degree of the disturbance, the physical environment, species composition and the life-history traits of the biota.

Estimates of ecosystem resilience are essential for evaluation of the effects of man-made activities. Attempts to measure resilience in ecosystems where spatio-temporal changes rather than constancy are the most influential feature involves the problem of finding representative control systems for comparison of when restoration has been accomplished. Benthic ecologists rarely enjoy the luxury of having good controls (Warwick 1986). Relevant controls, however, can be provided in field experiments designed to detect disturbance-induced changes at the community level. Sections of the ecosystem are experimentally disturbed and other sections are left undisturbed as controls. Repeated comparison between treatments and controls will then describe resilience in the disturbed patch. Models for community responses to perturbations may be erected from such experiments. Such models are important as a conceptual framework for understanding and evaluating the effect of pollutants in the environment.

Recolonization of soft sediment has been examined from various viewpoints, such as community establishment, succession and stability, deep sea biology and pollution (Sanders et al. 1980, Santos \& Simon 1980a, Arntz \& Rumohr 1982, Butman 1987, Grassle \& MorsePorteous 1987, Bakke et al. 1988, Palmer 1988 and references therein). Many studies on the effect of oil on benthic assemblages have been carried out after accidental oil spills. Most studies lack data on oil concentration and the resulting changes in chemical and physical parameters in the sediment both in time and space.

Here macrofauna recolonization of subtidal sediments in a eutrophicated and a non-eutrophicated fjord is reported. The focus is on community parameters. Oil depuration and physical changes of the sediment have been reported previously (Berge et al. 1987) and individual species responses will be described in another paper (Berge unpubl.).

\section{MATERIAL AND METHODS}

Experiments were performed in Norway on subtidal (23 $\mathrm{m}$ depth) muddy sediment in the Oslofjord and on a subtidal ( $20 \mathrm{~m}$ depth) area with shell sand in the Raunefjord (see Berge et al. 1987 for a more detailed site description). The experiments were performed by placing oiled and clean defaunated (frozen) sediment on the sea floor in experimental boxes each with a
Table 1 Sampling dates and number of boxes sampled

\begin{tabular}{|lrr|}
\hline & Oslofjord & Raunefjord \\
\hline Start of experiments & & \\
Date & 11 Apr 1980 & 18 Feb 1981 \\
No. control boxes submerged & 2 & 6 \\
No. oiled boxes submerged & 2 & 6 \\
First sampling & & \\
\hline Date & 8 Jul 1980 & 25 Jun 1981 \\
Experimental period (d) & 88 & 127 \\
No. control boxes sampled & 2 & 1 \\
No. oiled boxes sampled & 2 & 1 \\
Second sampling & & \\
Date & 11 Nov 1981 \\
Experimental period (d) & & 266 \\
No. control boxes sampled & & 2 \\
No. oiled boxes sampled & & 2 \\
Third sampling & & \\
Date & & 398 \\
Experimental period (d) & & 3 \\
No. control boxes sampled & & 398 \\
No. oiled boxes sampled & & \\
\hline
\end{tabular}

surface area of $0.2 \mathrm{~m}^{2}$ and a vertical side of $12.5 \mathrm{~cm}$. The progress of a particular box through time was not followed. In the Oslofjord, all boxes were retrieved after the experimental period, while in the Raunefjord identically treated boxes were collected sequentially. Table 1 shows number of boxes and sampling schedule. The contaminated boxes contained a $7.5 \mathrm{~cm}$ layer of homogenized sediment on top of which a $3 \mathrm{~cm}$ layer of sediment contaminated with unweathered North Sea crude oil was laid. The control boxes contained a $10.5 \mathrm{~cm}$ layer of untreated homogenized sediment. Preparation of the sediment in the boxes is described by Berge et al. (1987). In the Oslofjord and Raunefjord experiments the initial mean contents of oil in the top layer of the sediment were $3920 \mathrm{ppm}$ and $4520 \mathrm{ppm}$ (wet weight sediment) corresponding to 9940 and 17795 ppm (dry weight sediment) respectively (see Berge et al. 1987). Samples for determination of depth distribution of animals retained on a $250 \mu \mathrm{m}$ sieve (excluding nematodes and protozoa) were obtained from the boxes in situ by SCUBA divers using hand-operated corers (inner diameter $6 \mathrm{~cm}$ ). After core sampling, boxes were taken to the surface and the remaining sediment sieved for macrofauna (mesh size $=1 \mathrm{~mm}$ ). Sediment cores for temporary meiofauna analysis were sectioned at $3 \mathrm{~cm}$ intervals on the day of sampling. All faunal samples were preserved with $10 \%$ neutralized formalin and stained with Rose Bengal. In the Oslofjord experiments the fauna from both cores and total boxes were identified to species or lowest. attainable taxonomic level under a binocular microscope. In the Raunefjord only the total boxes were 
identified to species and the core samples to major taxon.

The total abundance (A), number of macrofauna species (S), wet weight biomass (B) (bivalves excluded because of small size) and the ratios $B / A^{*}\left(A^{*}=A-\right.$ number of bivalves) and $\mathrm{A} / \mathrm{S}$ were recorded and plotted for the oiled and control sediment. Samples were carefully blotted with tissue paper prior to biomass determination.

Following MacArthur \& Wilson (1963) the recolonization of islands is determined by the difference between immigration rate $(I)$ and extinction rate $(E)$ in the integral

$$
S_{t}=\int_{0}^{t}(I-E) d t
$$

where $S_{t}=$ mean number of species on the island at time $t$. This integral can be solved and the recolonization curve can be shown to be asymptotic and to have the form

$$
S_{t}=S\left(1-e^{-G t}\right)
$$

where $\mathrm{S}=$ mean equilibrium number of species on the island; and $G=$ a constant.

A recolonization curve of the form $S_{1}=S\left(1-e^{-G t}\right)$ was fitted to the data. The mean equilibrium numbers of species ( $\mathrm{S}$ ) in oiled and control boxes were established graphically by eye. An approximate estimate of $G$ was made by inserting $S$ and corresponding values of $S_{t}$ and $t$ into the equation $S_{t}=S\left(1-e^{-G t}\right)$ and solving for $G$. Based on the estimated values for $G$ and $S$ the time needed to reach $90 \%$ of saturation was calculated.

Mean values of I and $E$ were calculated by comparing the number of species added or deleted between 2 successive samplings for all possible combinations of boxes sampled during such a period. E was calculated both on a per-day and per-box basis (species $d^{-1}$ box ${ }^{-1}$; $\mathrm{S} / \mathrm{db}$ ) and on a per species, day and box basis (species species $^{-1} \mathrm{~d}^{-1}$ box $^{-1} ; \mathrm{S} / \mathrm{Sdb}$ ). For the purpose of this study I and E were calculated as the addition or loss of number of species, and not as originally defined by MacArthur \& Wilson (1963) as the number of propagules, a propagule being the minimum number of individuals capable of establishing a reproductive population.

Diversity of the macrofauna assemblages in the boxes was measured using the Shannon-Wiener diversity index $\left(\log _{2}\right)$ (Shannon \& Weaver 1963) and evenness using Pielou's index (Pielou 1966). In comparing diversity profiles (k-dominance curves) Lambshead et al. (1983) were followed. For analyzing multispecies distribution patterns (using double square root transformed species abundance data) the recommendations of Field et al. (1982) were followed using multidimen- sional scaling (MDS) ordination. Plots of the distribution of individuals among species in boxes (see Gray \& Pearson 1982) and Hurlbert's rarefaction curves (Hurlbert 1971) were also plotted. Polychaetes were classified in feeding groups according to Fauchald \& Jumars (1979).

\section{RESULTS}

\section{Oslofjord experiments}

Table 2 shows the basic community data where variability between replicates was large and mean values for the 2 treatments were not significantly different (2tailed t-test, $\mathrm{p}=0.05$ ). The distribution of individuals among species also shows a considerable variability for total box samples (Fig. 1A, B) and core samples (Fig. 1C, D). The k-dominance curves show that the assemblages in the 2 control boxes combined are slightly more diverse than in the contaminated boxes (Fig. 2A). Increased Shannon-Wiener diversity $(\mathrm{H})$ is indicated only in one of the 2 control boxes (Table 2A). No difference in diversity between treatments is indicated for the core samples (Fig. 2B, Table 2B).

As much as 96 to $98 \%$ of the total number of individuals in the core samples were found in the top $3 \mathrm{~cm}$ of the sediment. Juveniles or newly settled spat of Polydora spp., Cirratulidae, bivalves and Pholoe minuta were abundant in the core samples. More than $99 \%$ of the bivalves were newly settled Tellinacea (250 to $400 \mu \mathrm{m})$. No significant differences in mean total abundance between oiled and control sediment were found (Table 3); however, all groups except echinoderms had a higher density in oiled sediment.

\section{Raunefjord experiments}

Generally a clear difference in macrofauna community parameters in oiled and control boxes was seen (Table 4). The variability between replicates within each treatment at the end of the experiments was small but was higher in the oil-contaminated boxes. A total of 174 species were found in the boxes throughout the experiments. Numbers of species in total box samples were significantly higher in the control boxes during the experimental period and had increased to 76 ( $\mathrm{SD}=$ 3) and $52(\mathrm{SD}=4)$ in control and contaminated boxes respectively at the end of the experiments. The increase in species abundance had nearly culminated in the oil-contaminated boxes by the end of the experiments but was still increasing in the control boxes (Fig. 3). The fitted recolonization curves (Fig. 3) are described by the formulae 
Table 2. Mean values of community parameters in the Oslofjord experiments (start: 11 Apr 1980; end: 8 Jul 1980). Numbers in brackets are individual measurements. Differences between control and oiled sediment are indicated $(2$-tailed $\mathrm{t}$-test $)$ : $\mathrm{ns}=$ $p>0.05$. A: Macrofauna; B: core samples. Data from the 5 cores from each box are pooled. Depth distribution $=0$ to $3 \mathrm{~cm} ; s$ sieve $=$ $250 \mu \mathrm{m}+500 \mu \mathrm{m}$

\begin{tabular}{|c|c|c|c|}
\hline Parameter & Control & Oil & Sig \\
\hline \multirow{2}{*}{\multicolumn{4}{|c|}{$\begin{array}{l}\text { A. Total box samples } \\
\text { No. of species (S) }\end{array}$}} \\
\hline & & & \\
\hline Start & 0 & 0 & \\
\hline End & $15.5(19,12)$ & $16(12,20)$ & ns \\
\hline \multicolumn{4}{|c|}{ No. of individuals (A) } \\
\hline Start & 0 & 0 & \\
\hline End & $512(446,578)$ & $799(306,1291)$ & $\mathrm{ns}$ \\
\hline \multicolumn{4}{|c|}{ Evenness (J) } \\
\hline End & $0.57(0.71,0.43)$ & $0.41(0.45,0.37)$ & ns \\
\hline \multicolumn{4}{|c|}{ Diversity $(\mathrm{H})$} \\
\hline End & $2.28(3.01,1.55)$ & $1.62(1.63,1.60)$ & ns \\
\hline \multicolumn{4}{|c|}{ Biomass $\left(g\right.$ box $\left.{ }^{-1}\right)(B)$} \\
\hline End & $3.20(3.50,2.89)$ & $2.54(0.65,4.43)$ & ns \\
\hline \multicolumn{4}{|c|}{ B. Core samples } \\
\hline \multicolumn{4}{|c|}{ No. of species (S) } \\
\hline Start & 0 & 0 & \\
\hline End & $25(27,23)$ & $24(25,23)$ & ns \\
\hline \multicolumn{4}{|c|}{ No. of individuals (A) } \\
\hline Start & 0 & 0 & \\
\hline End & $2041(2571,1510)$ & $3130(3201,3058)$ & ns \\
\hline \multicolumn{4}{|l|}{ Evenness (J) } \\
\hline End & $0.45(0.42,0.48)$ & $0.42(0.44,0.40)$ & ns \\
\hline \multicolumn{4}{|c|}{ Diversity $(\mathrm{H})$} \\
\hline End & $2.08(1.98,2.17)$ & $1.92(2.03,1.81)$ & ns \\
\hline
\end{tabular}
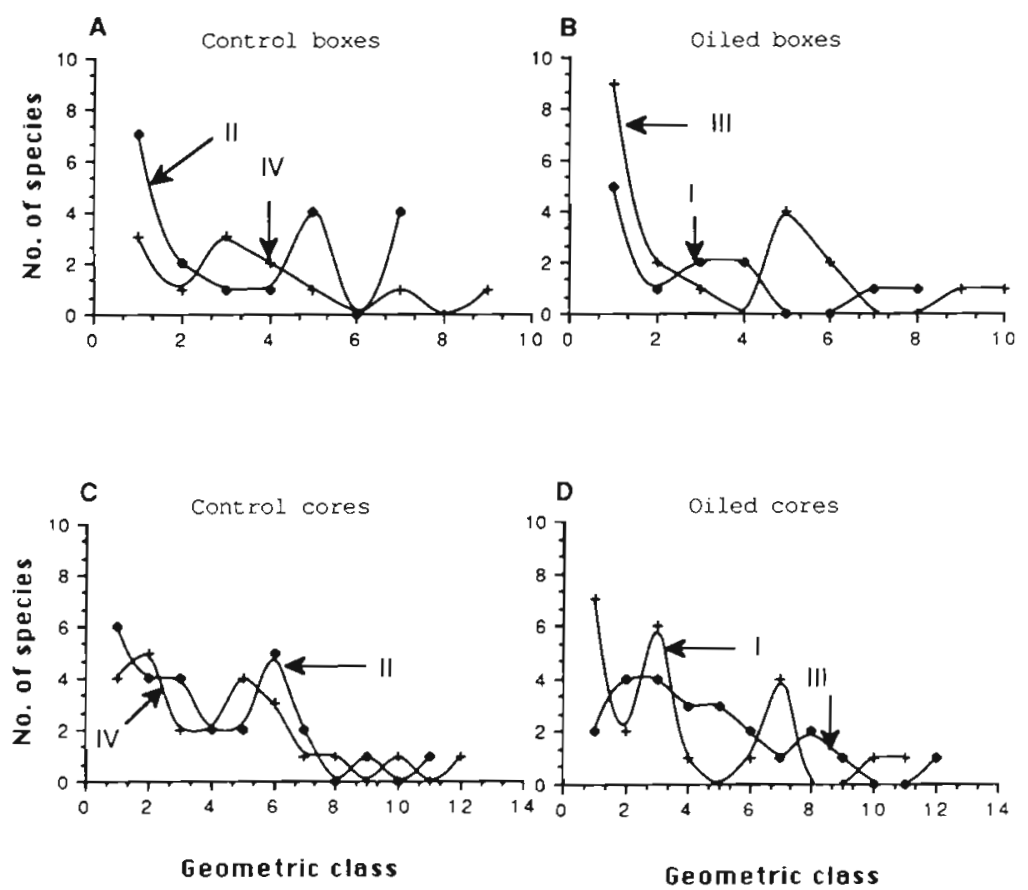

Fig. 1. Distribution of individuals among species for each box in the Oslofjord experiments. Box nos. are indicated. Geometric class $1=1$ individual; geometric class $2=2$ or 3 individuals; geometric class $3=4$ to 7 individuals geometric class $\mathrm{n}=2^{\mathrm{n}-1}$ to $2^{\mathrm{n}}-1$ individuals. (A) Total box, control; (B) total box, oil; (C) core samples, control; eometric class 

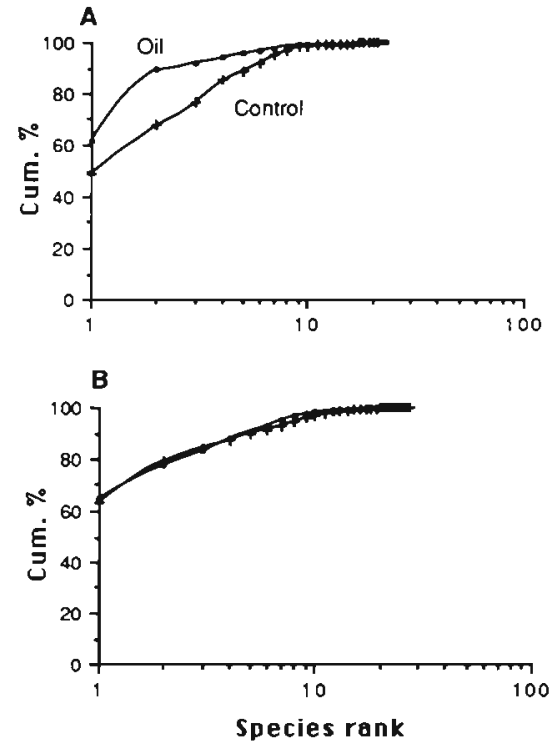

Fig. 2. K-dominance curves for the fauna in control sediment $(+)$ and oil-contaminated sediment $(\bullet)$ in the Oslofjord. (A) Total box samples; (B) core samples

Table 3. Number of individuals retained on $0.25 \mathrm{~mm}$ and $0.5 \mathrm{~mm}$ sieves from the 0 to $3 \mathrm{~cm}$ depth interval in cores from the Oslofjord in July 1980. Five replicates from each experimental box $(\mathrm{n}=10)$. ns: no significant (t-test, 2 -tailed, $p<0.05$ ) difference between mean density in control and oiled sediment

\begin{tabular}{|lrrrrr|}
\hline \multirow{2}{*}{ Taxon } & \multicolumn{2}{c}{ Control } & \multicolumn{2}{c}{ Oil } & \multirow{2}{*}{ Sig. } \\
& Mean & SD & Mean & SD & \\
\hline Bivalvia & 65.8 & 28 & 79.3 & 43.4 & ns \\
Polychaeta & 328.8 & 230 & 528.1 & 192.1 & ns \\
Echinodermata & 0.4 & & 0.4 & & \\
Crustacea & 14.2 & 8.7 & 18.6 & 11.3 & ns \\
Others & 0.8 & & 1 & & \\
Total & 410 & 250 & 627 & 224 & $\mathrm{~ns}^{\mathrm{a}}$ \\
a $\mathrm{p}=0.0554$ & & & & & \\
\hline
\end{tabular}

$$
\begin{aligned}
& \text { Oiled sediment: } S_{t}=55\left(1-e^{-0.009 t}\right) \\
& \text { Control sediment: } S_{t}=90\left(1-e^{-0.005 t}\right)
\end{aligned}
$$

and indicate that oil reduces the mean equilibrium number of species by $39 \%$, from 90 to 55 . The calculated time needed to reach $90 \%$ of saturation in the species numbers were $259 \mathrm{~d}$ in the oiled sediment and $466 \mathrm{~d}$ in the control sediment.

Total numbers of individuals per box were generally higher in control than in contaminated boxes (Table 4). After an initial increase during the first 4 mo, a clear decline was observed resulting in a total mean density of $529(\mathrm{SD}=13)$ and $276(\mathrm{SD}=43)$ in control and contaminated boxes respectively in March 1982 . The
Table 4. Mean values of macrofauna community parameters in boxes in the Raunefjord experiments. Numbers in brackets are standard deviation as \% of mean. Significant differences between control and oiled sediment are indicated (2-tailed t-test) for November and March data: ${ }^{\prime} p<0.05, \cdots p<0.01$,

\begin{tabular}{|c|c|c|c|}
\hline Parameter & Control & Oil & Sig. \\
\hline \multicolumn{4}{|l|}{ No. of species (S) } \\
\hline Start (Feb 1981) & 0 & 0 & \\
\hline Boxes (Jun 1981) & 52 & 32 & \\
\hline Boxes (Nov 1981) & 65 & 50 & $\cdot$ \\
\hline Boxes (Mar 1982) & $76(3.9 \%)$ & $52(7.69 \%)$ & $\cdots$ \\
\hline \multicolumn{4}{|l|}{ No. of individuals (A) } \\
\hline Start (Feb 1981) & 0 & 0 & \\
\hline Boxes (Jun 1981) & 1353 & 980 & \\
\hline Boxes (Nov 1981) & 658 & 577 & ns \\
\hline Boxes (Mar 1982) & $529(2.45 \%)$ & $276(15.5 \%)$ & $\cdots$ \\
\hline \multicolumn{4}{|l|}{ Evenness (J) } \\
\hline Boxes (Jun 1981) & 0.38 & 0.21 & \\
\hline Boxes (Nov 1981) & 0.77 & 0.62 & $\cdot$ \\
\hline Boxes (Mar 1982) & $0.82(2.4 \%)$ & $0.78(3.42 \%)$ & ns \\
\hline \multicolumn{4}{|l|}{ Diversity $(\mathrm{H})$} \\
\hline Boxes (Jun 1981) & 2.15 & 1.00 & \\
\hline Boxes (Nov 1981) & 4.66 & 3.50 & $\cdot$ \\
\hline Boxes (Mar 1982) & $5.13(2.9 \%)$ & $4.49(4.6 \%)$ & $\cdot$ \\
\hline \multicolumn{4}{|l|}{ Biomass $\left(g\right.$ box $\left.{ }^{-1}\right)(B)$} \\
\hline Start (Feb 1981) & 0 & 0 & \\
\hline Boxes (Jun 1981) & 4.32 & 4.83 & \\
\hline Boxes (Nov 1981) & 9.01 & 4.00 & $\cdots$ \\
\hline Boxes (Mar 1982) & $6.9(17.7 \%)$ & $1.41(35.5 \%)$ & $\cdot$ \\
\hline
\end{tabular}
$\mathrm{ns}=\mathrm{p}>0.05$

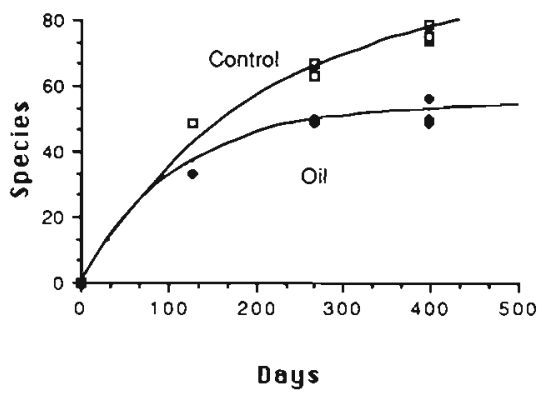

Fig. 3. Total number of species in control sediment and oilcontaminated sediment during experiments in the Raunefjord. Note that the fitted curves are of the form $S_{t}=S\left(1-e^{-G t}\right)$

difference in density between the 2 treatments was only significant at the end of the experiments. This was caused mainly by an initial population increase of the polychaete Polydora socialis which dominated both in control and oil-contaminated boxes in June and November and was followed by a population crash by March 1982. A significantly higher density in the control boxes is found when $P$. socialis is excluded (Fig. 4).

Both diversity $(\mathrm{H})$ and evenness $(\mathrm{J})$ were lower in the contaminated sediment in June and November 1981 (Table 4). By March 1982, however, evenness was not 


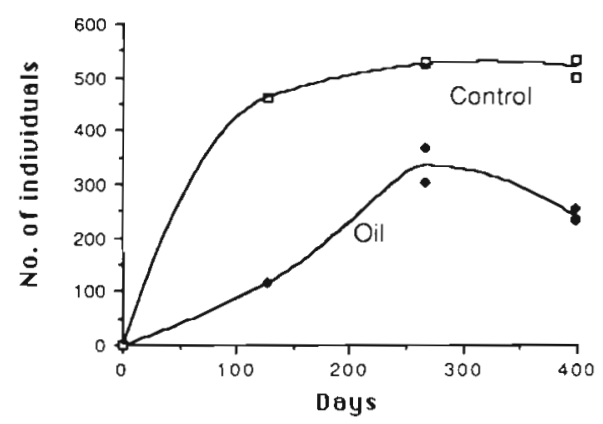

Fig. 4. Total number of individuals excluding Polydora socialis during experiments in the Raunefjord
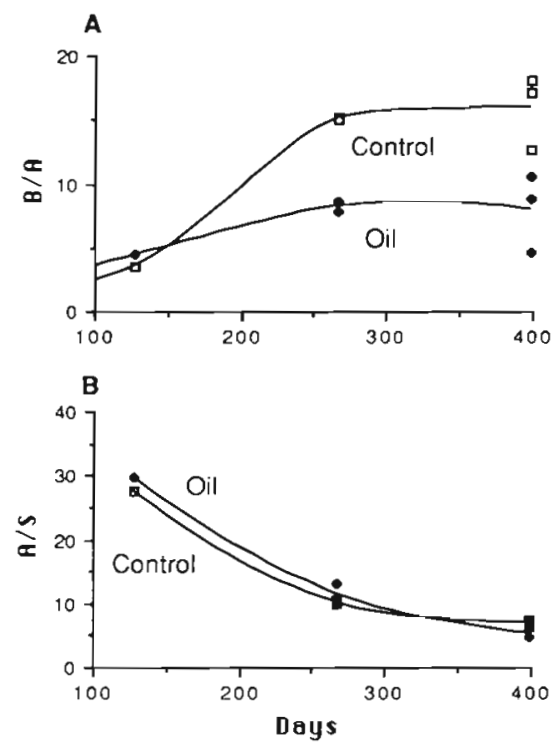

Fig. 5. (A) Biomass/abundance and (B) abundance/species ratios in oiled and control sediments during experiments in the Raunefjord. Note that bivalves are excluded in the calculation of $\mathrm{B} / \mathrm{A}$.

significantly different in the 2 treatments whereas diversity was.

Biomass (excluding bivalves) were significantly higher in control boxes in November 1981 and March 1982 but probably not in June 1981 (Table 4). The highest biomass in control boxes were found in November 1981 and in contaminated sediment in June 1981.
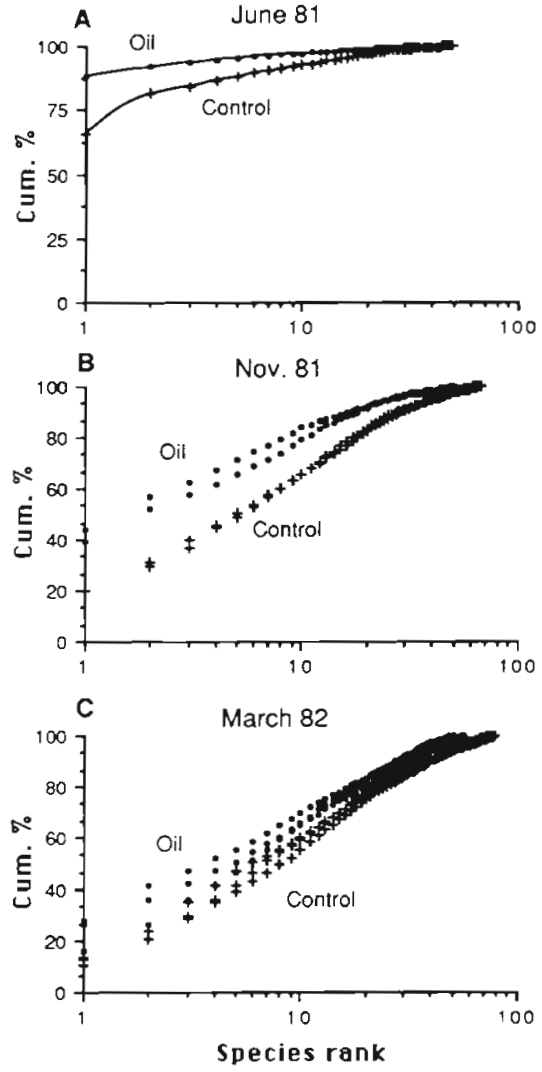

Fig. 6. K-dominance curves for the fauna in each box in the Raunefjord. (+) Control sediment; (•) oil-contaminated sedjment. (A) June; (B) November; (C) March

Biomass/abundance ratios (Fig. 5A) were similar in June but were significantly different (ANOVA, $\mathrm{p}<0.05\}$ in oiled and control sediment both in November (266 d) and in March (398 d). Abundance/ species ratios were not significantly different in the 2 treatments during the experimental period (Fig. 5B).

Calculated immigration rates (I) and extinction rates (E) were not significantly different in control and oiled boxes for the period June to November (Table 5). Recolonization was however initially (February to June 1981) somewhat higher in the control boxes, indicated by the higher species numbers in the control sediment on the first sampling. During the period November to

Table 5. Immigration rate (I) and extinction rate (E) in control and oil-contaminated boxes during time intervals June to November 1981 and November 1981 to March 1982. "Significant $(p<0.05)$ difference between control and oiled sediment. Number of replicates: Jun to Nov $=2$, Nov to Mar $=6$. S: species; d: day; b: box; O: oiled boxes; C: control boxes

\begin{tabular}{|c|c|c|c|c|c|c|}
\hline \multirow[t]{2}{*}{ Period } & \multicolumn{2}{|c|}{$\begin{array}{l}\text { Immigration } \\
\text { (S/db) }\end{array}$} & \multicolumn{2}{|c|}{$\begin{array}{l}\text { Extinction } \\
\text { (S/db) }\end{array}$} & \multicolumn{2}{|c|}{$\begin{array}{l}\text { Extinction } \\
(\mathrm{S} / \mathrm{Sdb})\end{array}$} \\
\hline & 0 & C & 0 & C & 0 & C \\
\hline Jun-Nov & 0.27 & 0.27 & 0.151 & 0.133 & 0.0048 & 0.0027 \\
\hline Nov-Mar & 0.174 & $0.236^{\circ}$ & 0.163 & 0.155 & 0.0033 & $0.0024^{\circ}$ \\
\hline
\end{tabular}


Fig. 7. Hurlbert's rarefaction plots [expected number of species $E\left(S_{n}\right)$ as a function of number of individuals] for each experimental box in the Raunefjord.

(A) Control boxes; (B) oiled boxes
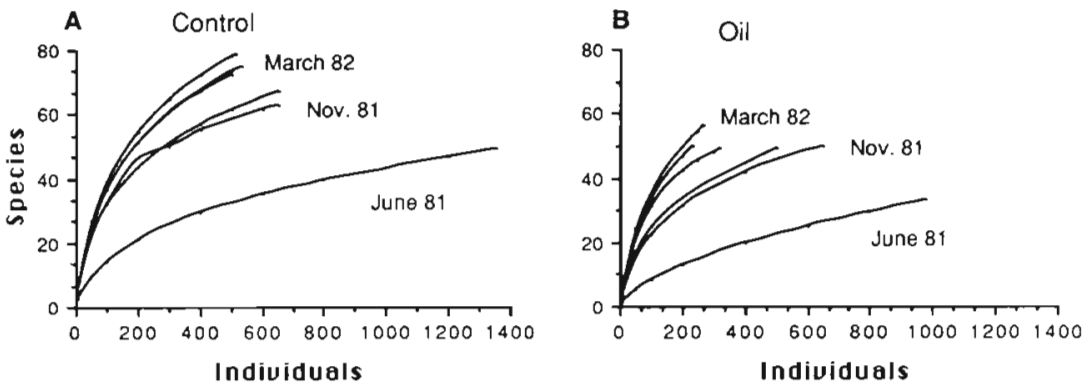

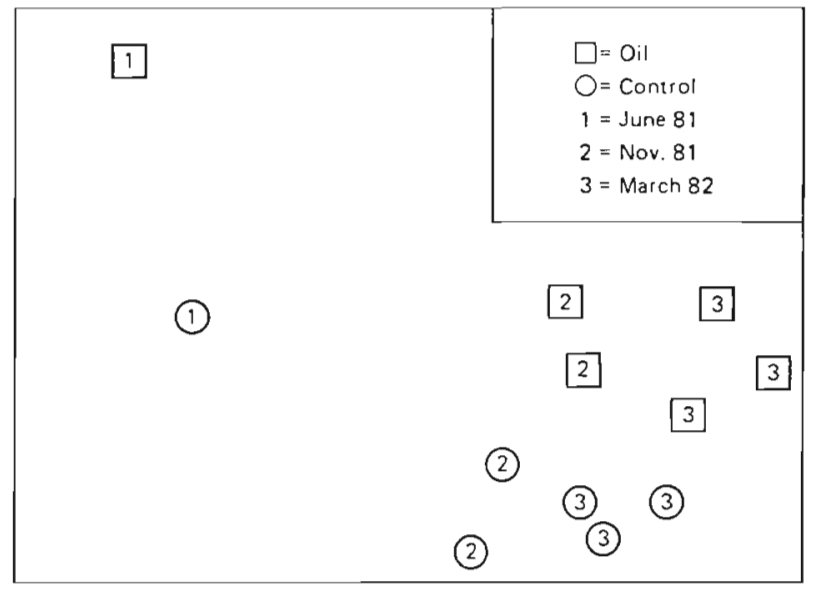

Fig. 8. Multidimensional scaling (MDS) ordination for macrofauna data from the boxes in the Raunefjord experiment

March the immigration rate (I) was significantly higher in control boxes whereas the extinction rate (E) was significantly higher in the oiled boxes when calculated on a per species basis (S/Sdb) (Table 5).

$\mathrm{K}$-dominance curves showed an increasing diversity and a reduction in dominance with time both in control and oil-contaminated sediment (intercept with $y$-axis moves towards origo) and the curves for the 2 treatments tended to converge by March 1982 (Fig. 6A to $\mathrm{C})$.

Hurlbert's rarefaction curves show a clear timerelated effect in both treatments, with a high abundance (A) and low species numbers (S) in the first part of the experimental period, shifting to a low A and high $\mathrm{S}$ at the end of the experiment (Fig. 7). The plots for replicate boxes varied little. The effects of oil were clear and consistent and showed lower $\mathrm{E}(\mathrm{Sn})$ values in the oiled boxes on all 3 samplings.

The MDS plot showed that assemblages in the boxes changed both with time and oil treatment (Fig. 8). The replication within treatments was good with successional changes moving from left to right and pollution effects being evident vertically.

The distribution of individuals among species showed a maximum of 10 geometric classes after 4 mo both in contaminated and control sediment (Fig. 9A). After 9 mo (Fig. 9B) the number of geometric classes was reduced to 9 and 8 in contaminated and control sediment respectively and reduced further to 7 for both treatments after 13 mo (Fig. 9C). The highest number of species was found in geometric class 1 both in control and contaminated sediment. A significantly lower number of species were found in contaminated sediment than in control sediment for most geometric
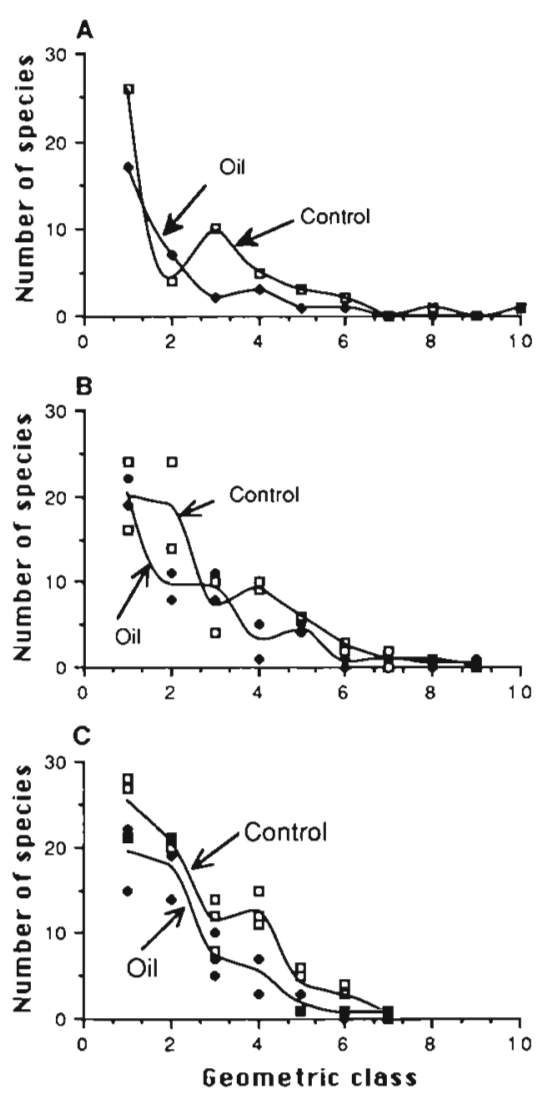

Fig. 9. Distribution of individuals among species in individual boxes in the Raunefjord for the fauna in (ㅁ) control sediment and $(\bullet)$ oil-contaminated sediment. Geometric classes as in Fig. 1. Interpolated curves for treatments are drawn. (A) June 1981; (B) November 1981; (C) March 1982 
classes. Only for geometric class 2 in June and 3 in November were numbers of species higher in contaminated sediment.

Different feeding groups of macrofaunal polychaetes were affected differently in the course of the experiment (Figs. 10 and 11). None of the major feeding groups showed higher densities in the oiled sediment than in the control sediment; thus no stimulation occurred. Generally the oil/control ratio for number of individuals within each feeding group showed a large variation in June and November and had converged to values in the range 0.35 to 0.52 by March (398 d) except for subsurface deposit feeders where the ratio was as low as 0.16 .

Figs. 10 and 11 show that for all feeding groups except the interface feeders (species living on the surface of the sediment which can collect food particles both from the water just above the sediment and from the sediment surface, e.g. Polydora socialis) the increase in number of individuals was initially much larger in the control boxes than in the oil-contaminated
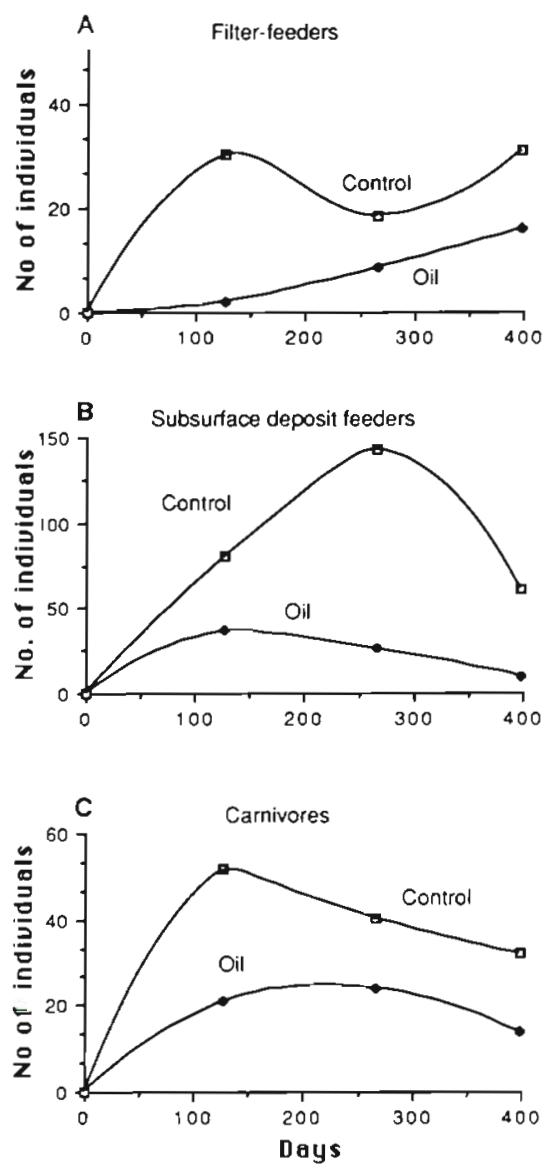

Fig. 10. Number of (A) filter-feeders, (B) subsurface deposit feeders, and (C) carnivores during the experiments in the Raunefjord boxes. For the interface feeders (mainly the opportunistic $P$. socialis), however, densities were approximately the same in oiled and control sediment throughout the experimental period (Fig. 11B). The numbers of individuals of filter feeders (Fig. 10A) and surface deposit feeders (Fig. 11A) in control and oil-contaminated sediment followed the same pattern with a gradual increase in abundance in the contaminated sediment throughout the experimental period and a initially larger increase in the control sediment followed by a period of slight reduction or stabilization. The largest relative difference between control and oiled sediment were seen for the subsurface deposit feeders (Fig. 10B).

After 4 mo the numbers of filter-feeders and surface deposit feeders were most severely reduced (Figs. 10A and 11A) whereas the interface-feeders were least reduced (11B). At the end of the experiment the subsurface deposit feeders were most severely reduced whereas the other feeding groups were less but similarly effected.

Oil affected recruitment of different feeding groups, integrated over the whole experimental period, and based on the oil/control ratio of individuals, in the following decreasing order: subsurface deposit feeders, carnivores, filter feeders, surface deposit feeders, surface deposit feeders/filter feeders.

The core samples in the Raunefjord were dominated by crustaceans (mainly harpacticoid copepods) and polychaetes (mainly newly settled Polydora spp.) (Table 6). Except for bivalves a higher density was found in oiled sediment than in control sediment (Table 6). In the core samples 90 to $94 \%$ of the individuals were found in the uppermost $3 \mathrm{~cm}$ of the sediment.

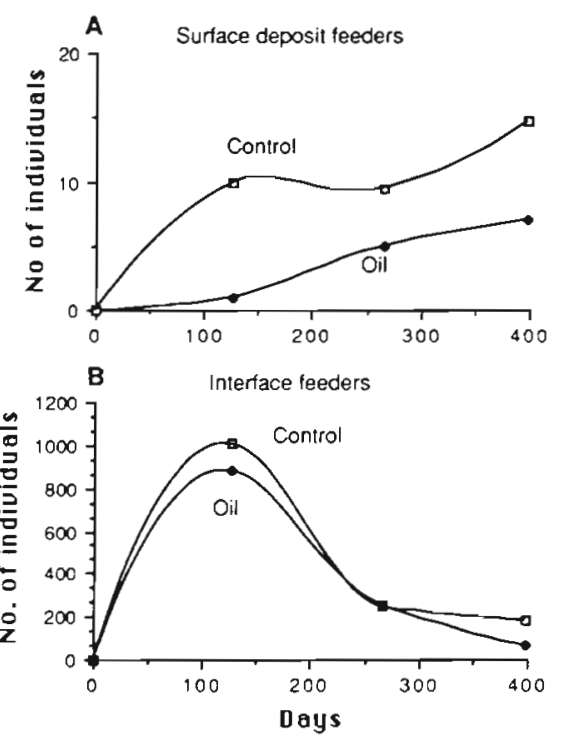

Fig. 11. Number of (A) surface deposit feeders, and (B) interface feeders during the experiments in the Raunefjord 
Table 6. Number of individuals retained on $0.25 \mathrm{~mm}$ and $0.5 \mathrm{~mm}$ sieves from the 0 to $3 \mathrm{~cm}$ depth interval in cores from the Raunefjord in March 1982. One replicate from each experimental box $(n=3)$. ' Significant (t-test, 2-tailed, $p<0.05$ ) difference between mean density in control and oiled sediment

\begin{tabular}{|lcrrr|}
\hline \multirow{2}{*}{ Taxon } & \multicolumn{2}{c}{ Control } & \multicolumn{2}{c|}{ Oil } \\
& Mean & \multicolumn{1}{c}{ SD } & Mean & SD \\
\hline Bivalvia & 8.3 & 2.3 & 2.7 & $1.2^{\circ}$ \\
Polychaeta & 51 & 14.7 & 70.7 & 1.2 \\
Echinodermata & 0.7 & 0.6 & 1.3 & 1.5 \\
Crustacea & 28 & 10.1 & 76.7 & $25.5^{\circ}$ \\
Others & 2.0 & 1.7 & 4.7 & 1.2 \\
Total & 90 & 7.5 & 162.7 & $21.5^{\circ}$ \\
& & & & \\
\end{tabular}

\section{DISCUSSION}

\section{Experimental design}

The design of these experiments was based on the assumption that identically treated boxes behave similarly in terms of recolonization events after they have been submerged. The probability of replicate boxes diverging because of stochastic processes is expected to increase with time until the variability approaches that of the ambient community. Replicability between boxes is thus best tested at the end of the experiments. The variability seen among boxes within treatments was mainly caused by stochastic elements of recruitment, less likely by biological interactions in the sediment. Homogenization of the sediment prior to the experiments should have reduced biological variability caused by physical and chemical variability to a minimum. The community data showed little variability at the end of the experiments in the Raunefjord. The assumption that identically treated boxes behave similarly in terms of recolonization events was, thus, fulfilled here. In the Oslofjord experiments the replication variance was larger (Table 2A). Variability may increase after oil contamination (Sanders et al. 1980) and may explain some of the variability observed in the oiled sediment.

The defaunation and homogenization of the sediment in the control boxes is itself a type of disturbance since it destroys the original stratification, structure and texture of the sediment and its surface. Local-scale disturbance is however a common phenomenon in sedimentary environments and may arise from physical, chemical and biological events like hypoxia, deposition and resuspension of sediment, bioturbation, pelletization and feeding activity (Probert 1984, and references therein). In addition to the physical treatment of the sediment described above, the oil repre- sents a chemical and physical disturbance which results in primary toxic effects and secondary changes in sediment properties including organic enrichment (Berge et al. 1987) which may have influenced recolonization more than the toxicity of the oil directly.

There were no dramatic effects of the added oil in the Oslofjord, due in part to the high variability between replicate boxes (Table 2 ). The community structure found in the control boxes and in the oil-contaminated boxes was roughly similar to the community structure of the sediment outside the boxes (Berge \& Valderhaug 1983). Thus restoration of major biological features of the community took less than 3 mo in an area with a benthic fauna typical for a eutrophicated fjord. Based on reported effects of hydrocarbons on benthic communities (Dixon 1987) it was surprising that the effect of the added oil was not dramatic, especially as the oil content in the sediment was high (3920 ppm wet wt) and was not reduced during the experimental period (Berge et al. 1987). Despite the fact that densities were reduced for some of the taxa for the total box samples (Berge unpubl.), it is concluded that the stress added to the system by the addition of oil did not affect the system profoundly and thus supports the notion that communities with few species, low diversity, and high dominance and high reproduction rates are more stress tolerant (have a higher resilience) than more complex systems (Jernlov \& Rosenberg 1976).

The oil added to sediments in the Raunefjord reduced the mean equilibrium number of species $S_{(e)}$ from 90 to 55. The number of species increased significantly in the control boxes between November 1981 and March 1982. This indicates that absence of settling larvae was not responsible for the lack of increase in species in oiled boxes during the last part of the experimental period. The sediment was stable and unfavorable during this period resulting in no increase in the number of species. Full restoration after an environmental disturbance therefore cannot be claimed simply on the basis that an asymptotic number of species has been found. It is expected, however, that the equilibrium number of macrofauna species in the oiled sediment would have increased eventually as the oil was degraded/depurated but over what time-scale cannot be predicted. It is obvious that much longer times are needed to achieve conditions approaching those of the control. When equilibrium is reached, cyclic fluctuations may, however, still be present (Arntz \& Rumohr 1982) and densitydependent processes may become significant resulting in a slight loss of species (Simberloff 1969, Hughes 1984). No such loss in the species numbers was seen in the Raunefjord and may indicate that equilibrium was not obtained or was only recently reached. With increasing time the probability of stochastic disturbance increases also (Santos \& Simon 1980a, b). 
From these experiments restoration of community structure in a patch similar to the boxes will after contamination with 4520 ppm of crude oil take at least 14 mo. Although the amount of oil added was initially somewhat lower in the Oslofjord experiments than in the Raunefjord experiment and may explain some of the difference in macrofauna response, the oil depurated faster in the Raunefjord (reduced to $63 \%$ of initial amount after $4 \mathrm{mo}$; Berge et al. 1987). No depuration was reported in the Oslofjord (Berge et al. 1987). It is therefore believed that the differences in macrofauna responses cannot alone be explained by the difference in the amount of oil added. It is concluded that the restoration of the benthic macrofauna after oil-contamination of sediment takes considerably longer time in a non-eutrophicated area than in a eutrophicated areas. On the other hand, oil depuration may be faster under non-eutrophicated conditions (Berge et al. 1987). Because the Raunefjord is non-eutrophicated there has been little selection or preconditioning among species to withstanding the conditions caused by or resembling eutrophication.

Effects of oil on benthic macrofaunal communities range from severe effects within hours, to effects detectable for years after the oil spill (Sanders et al. 1980) or trophic enrichment leading to increased densities (Spies \& Davies 1979, Davies \& Spies 1980, Spies et al, 1988). Spies et al. (1988) found in a recolonization experiment that crude oil $(0.1 \%)$ enhanced meiofauna abundance. In the same experiment it was found that the total number of macrofauna individuals (Capitella spp. excluded) was reduced with increasing amounts of oil added $(0.1,1$ and $5 \%)$. At the highest concentrations (5\%) of both oil and kelp (separate and together) there was a suppression in the number of macrofauna species, whereas the meiofauna where less affected and even showed enhanced abundance at low oil concentrations. Toxicity per se was claimed to have contributed little to the outcome of the experiments and the by-products $\left(\mathrm{H}_{2} \mathrm{~S}\right)$ of bacterial metabolism of added organic material were suggested to have played an important role in the reduction of some groups. Spies et al. (1988) concluded that the results of their experiments were largely consistent with the view that the response of the benthic populations to the crude oil were similar to those expected from other sources of organic matter. Positive effects caused by trophic enrichment was not detected at the macrofauna community level in these experiments but may have played a role for the increased densities of small sized animals found in the core samples in the Raunefjord.

Different diversity indices do not necessarily order different communities similarly along an apparent intrinsic diversity scale (Lambshead et al. 1983). Diversity has, apart from pollution, also been related to various biological attributes of a community. Differences in diversity between the treatments could have been caused by differences in one or a combination of different attributes of a community (predation, competition, evolution, recruitment etc.). The community in the boxes was in a early recruitment phase with few large predators and a relative high organic carbon content in the sediment. This suggested that the species in the boxes were not interacting (predation. disturbance, resource competition) strongly. Thus, inter- and intraspecific interactions are not likely explanations for the difference in diversity between oiled and control sediment. Immigration rates were identical in the 2 treatments between June and November and may indicate that species recruitment was similar in the 2 treatments during this part of the experiments, but not after November. Differences in recruitment potential could thus not explain differences in diversity during this period. Measured extinction rates for the whole period were however highest in the oiled boxes. The difference in macrofauna diversity was thus probably caused by toxic effects of the oil directly or by secondary effects from oil on other physical and chemical properties in the sediment. This toxicity probably increased mortality to a degree sufficient to also effect extinction rates.

Diversity measure, $\mathrm{k}$-dominance plots, distribution of species among individuals and Hurlbert's rarefaction curves were all able to distinguish control sediment from oil-contaminated sediment in the Raunefjord.

Because of the more severe conditions deeper in the sediment in the oiled boxes (Berge et al. 1987) and because the conditions first ameliorate near the surface of the sediment, it is expected that subsurface-living animals, after the time needed to penetrate into the sediment (and confronted with the conditions there), would be affected more severely than would surface deposit feeders and interface feeders, whereas filter feeders are expected to be the least affected group, except initially after an oilspill when hydrocarbons are introduced only to the sediment surface and on particles in the bottom water. By living and feeding on or above the sediment surface where the sediment is first ameliorated, they avoid the more severe conditions that develop in the sediment caused by oil penetration. Filter-feeders and surface deposit feeders were however most vulnerable initially, probably because the oil concentration in the top few $\mathrm{mm}$ of the sediment was still high in June (Berge 1987).

Interface feeders were not seriously affected, probably since this group were dominated by the opportunistic spionid Polydora socialis. The genus Polydora is known to be an relatively early recolonizer after sediment disturbances; worms live in tubes which may protect them from unfavorable conditions in the sediment. 
In the Raunefjord, subsurface deposit feeders were the most severely affected feeding group on the 2 last samplings as predicted above; however, on the first sampling both filter feeders and surface deposit feeders were clearly more affected. All recolonizing animals living in or on the sediment, both adults and larvae, are first confronted with the sediment surface and the conditions there. This probably implies that recolonizing subsurface deposit feeders cannot select or reject subsurface conditions in the oiled boxes, prior to settlement, unless they can detect fluxes out of the sediment indicative of the conditions there. Settlement of the larvae of Capitella sp. I is promoted by hydrogen sulfide originating from sediments (Cumo 1985, Dubilier 1988). Capitella was found in similar and low numbers in both the control and oiled boxes (Berge 1990), thus, an assumed increase in hydrogen sulfide concentration in the oiled boxes was not sufficient to increase settlement in the oiled boxes. Subsurface deposit feeders are probably generally also better adapted to low redox conditions than the feeding groups living near the surface. This may explain the somewhat less negative effect on this feeding group on the first sampling compared to the other groups.

From the results emerges a tentative model for early polychaete recolonization of severely oil-contaminated sediment where oil has penetrated into the sediment: macrofauna filter-feeders and surface deposit feeders are initially severely affected, possibly because they are less tolerant than the subsurface deposit feeders to for example low redox potential and $\mathrm{H}_{2} \mathrm{~S}$. As the surface sediments recover by depuration of hydrocarbons filter feeders and surface deposit feeders gradually increase in abundance whereas subsurface deposit feeders, as they increase in size and penetrate deeper down in the sediment, are confronted with the less favorable conditions there (low redox potential, high oil content), and as a consequence are reduced in abundance.

Interface feeders were dominated by opportunistic spionids which initially settled in high abundance. High abundance of opportunistic spionids in the oiled boxes was possibly due to their tubes creating an oxic area protected from the unfavorable conditions in the sediment.

Larval settlement onto soft sediment is primarily controlled by the complementary processes of habitat selection (microhabitat) and passive deposition (largescale) (Butman 1987). In all boxes the part of the settlement process related to passive deposition is assumed to be similar since the boxes were situated within a limited area on a near horizontal bottom and should thus lie in a relatively homogeneous hydrodynamic regime. Two distinct patterns exist for recruitment of meiofauna via water-column pathways: active entry into the water and passive erosion/resuspension from the sediment, both with subsequent water-borne transport to new substrates. Numerous colonization studies have demonstrated that meiofauna may repopulate areas in hours to days (see Palmer 1988 and references therein) whereas macrofauna colonize more slowly. Thus even unfavorable sediment probably has higher settlement rates from meiofauna than from macrofauna. In an area where extinction rates for meiofauna and macrofauna are comparable, the observed difference between oiled and control sediment would be less for meiofauna than for macrofauna. This mechanism could explain some of the differences in oil effects on meiofauna and macrofauna.

Differences in habitat selection, mortality or resuspension of newly settled larvae are possible explanations for the difference in faunal densities between the 2 treatments. Signs of more resuspension in the control boxes than in the oiled boxes were detected (Berge et al. 1987). An increase in the resuspension of newly settled meiofauna in the control may thus be an alternative to the enrichment hypothesis in explaining the increased density in the core samples in the oiled boxes (at least in the Raunefjord). Differences in passive deposition and resuspension of settling larvae are however not a likely explanation for the reduced density of macrofauna in the oiled boxes. Calculated immigration rates during the period June to November were however similar in both treatments, whereas during the period November to March they were somewhat higher in the control box. This may reflect that the early immigrants are less discriminating than the late immigrants. Immigration rates are reduced when the distance to source communities from where larvae and adults can immigrate is increased (MacArthur \& Wilson 1963). In the experiments only small areas $\left(0.2 \mathrm{~m}^{2}\right)$ of the sediment were treated, thus mimicking situations where the disturbing agent is patchily distributed. Where considerably larger areas are oil-contaminaed thus increasing distance to source communities immigration rates are expected to be lower near the center.

Increased mortality in the oiled boxes is indicated by a higher extinction rate in the oiled boxes (Table 5). This points to differential mortality after the initial settlement as the most probable explanation for macrofauna community differences in the boxes in the Raunefjord

The concentrations used were substantial compared to background levels in the North Sea $(<10 \mathrm{ppm})$ and even for concentrations found over larger areas after major oil spills (Besliers et al. 1980), hence subtidal areas likely to receive such levels of contamination are not expected to be extensive. In the Raunefjord experiments $33 \%$ of the oil remained in the sediment after 
398 d (Berge et al. 1987) whereas $80 \%$ was lost during the first $40 \mathrm{~d}$ in similar experiments where oil was distributed in the top $2 \mathrm{~mm}$ of the sediment (Davies \& Tibbetts 1987), thus oil on the sediment surface is more easily depurated than oil deeper down in the sediment. If similar amounts of oil were introduced to an intact mature community, the effect might be less if the organisms could temporarily avoid the contamination by moving deeper into the sediment until the oil has depurated or is degradated. If oil is bioturbated into the sediment, the effects are likely to be more permanent (years) at least on the subsurface living fauna.

The effects of oil on macrofauna in the Raunefjord are seen in most of the community parameters through comparisons with controls. It would however, be difficult to point to community characteristics indicating oil effects if only data from the oiled boxes were available.

Acknowledgements. These experiments were executed under the Norwegian Marine Pollution and Monitoring Program (Project no. 203). Manuscript preparation was finalized while employed at Norwegian Institute of Water Research (NIVA) through research grant no. E-87720. I thank Torleif Brattegard for the use of facilities at the Department of Marine Biology, University of Bergen, Terje Kleppe for organizing and performing excellent diving assistance, Arnfinn Skadsheim and Hartvig Christie for their assistance in the field and in the laboratory, and Susan Garner-Price and Bjørn Tunberg for their help in identifying amphipods and bivalves respectively. I further thank Richard Warwick for performing some of the community structure analysis, and John S. Gray, Torgeir Bakke and Brage Rygg for their comments on the manuscript. Finally I thank John S. Gray for his support during the years I have been at the Department of Biology, University of Oslo without which this contribution would not have appeared.

\section{LITERATURE CITED}

Arntz, W. E., Rumohr, H. (1982). An experimental study of macrobenthic colonization and succession, and the importance of seasonal variation in temperate latitudes. J. exp. mar. Biol. Ecol. 64: 17-45

Bakke, T., Berge, J. A., Naess, K, Oreld, F., Reiersen, L. O., Bryne, K. (1988). Long term recolonization and chemical change in sediments contaminated with oil-based drill cuttings. In. Engelhardt, F. R., Ray, J. P., Gillam, A. H. (eds.) Drilling wastes. Elsevier Applied Science, London, p. $521-544$

Berge, J. A., Lichtenthaler, R. G., Oreld, F. (1987). Hydrocarbon depuration and abiotic changes in artificially oil contaminated sediment in the subtidal. Estuar coast. Shelf Sci. 24: 567-583

Berge, J. A., Valderhaug, V A. (1983). Effect of epibenthic macropredators on community structure in subtidal organically enriched sediments in the inner Oslofjord. Mar. Ecol. Prog. Ser. 11: 15-22

Besliers, A., Birrien, J. L., Cabioch, L, Larsonneur, C., Le Borgne, L. (1980). La pollution des Baies de Morlaix de Lannion par les hydrocarbures de l'Amoco Cadiz': Repar- tition sur les fonds et evolution. Helgoländer Meeresunters. 33: 209-224

Bonsdorff, E. (1983). Recovery potential of macrozoobenthos from dredging in shallow brackish waters. Proceedings 17 th European Marine Biology Symposium, Brest, France. Oceanol. Acta, p. 27-32

Butman, C. A (1987). Larval settlement of soft-sediment invertebrates: the spatial scales of pattern explained by active habitat selection and the emerging role of hydrodynamic processes. Oceanogr. mar. Biol. A. Rev. 25: 113-165

Cuomo, M. C. (1985). Sulphide as a larval settlement cue for Capitella capitata. Biogeochemistry 1: 169-181

Dauer, D. M., Simon, J. L. (1976). Repopulation of the polychaete fauna of an intertidal habitat following natural defaunation: species equilibrium. Oecologia (Berl.) 22: 99-117

Davies, P. H., Spies, R. B. (1980). Infauna benthos of a natural petroleum seep: study of community structure. Mar Biol. 59: $31-41$

Davies, J. M., Tibbetts, P. J. C. (1987). The use of in situ benthic chambers in study of fate of oil in sublittoral sediments. Estuar. coast. Shelf Sci. 24: 205-223

Dixon, I. M. T. (1987). Experimental application of oil-based muds and cuttings to seabed sediments. In: Kuiper, J., Van den Brink, W J. (eds.) Fate and effects of oil in marine ecosystems. Martinus Nijhoff Publishers, Dordrecht, p. $133-150$

Dubilier, N. (1988). $\mathrm{H}_{2} \mathrm{~S}$ - a settlement cue or a toxic substance for Capitella sp. I larvae. Biol. Bull. mar. biol. Lab., Woods Hole 174: 30-38

Fauchald, K., Jumars, P. A. (1979). The diet of worms: a study of polychaete feeding guilds. Oceanogr. mar. Biol. A. Rev. 17: $193-284$

Field, J. G., Clarke, K. R., Warwick, R. M. (1982). A practical strategy for analysing multispecies distribution patterns Mar. Ecol. Prog. Ser. 8: 37-52

Grassle, J. F., Morse-Porteous, L. S. (1987). Macrofaunal colonization of disturbed deep-sea environments and the structure of deep-sea benthic communities. Deep Sea Res. 34: $1911-1950$

Gray, J. S., Pearson, T H. (1982). Objective selection of sensitive species indicative of pollution-induced change in benthic communities. I. Comparative methodology. Mar Ecol. Prog. Ser. 9: 111-119

Hughes, R. G. (1984). A model of the structure and dynamics of benthic marine invertebrate communities. Mar. Ecol. Prog. Ser 15: 1-11

Hurlbert, N. (1971). The non-concept of species diversity. Ecology 52: 577-586

Jernløv, A., Rosenberg, R. (1976). Stress tolerance of ecosystems. Envir. Conserv. 3: 43-46

Johnson, R. G. (1972). Conceptual models of benthic marine communities. In: Schopf, T. J. M. (ed.) Models of paleobiology. Freeman Cooper \& Co, San Francisco, p. 148-159

Lambshead, P. J. D., Platt, H. M., Shaw, K. M. (1983). The detection of differences among assemblages of marine benthic species based on an assessment of dominance and diversity. J nat. Hist. 17: 859-874

MacArthur, R. H., Wilson, E. O. (1963). An equilibrium theory of insular zoogeography. Evolution 17: 373-387

Nerini, M. K., Oliver, J. S. (1983). Gray whales and the structure of the Bering Sea benthos. Oecologia (Berl.) 59: 224-225

Palmer, M. A. (1988). Dispersal of marine meiofauna: a review and conceptual model explaining passive transport and active emergence with implications for recruitment. Mar Ecol. Prog. Ser 48: 81-91 
Pearson, T H., Rosenberg, R. (1978). Macrobenthic succession in relation to organic enrichment and pollution of marine environments. Oceanogr. mar. Biol. Ann. Rev. 16: 229-311

Pielou, E. C. (1966). The measurement of diversity in different types of biological collections. J. theoret. Biol. 13: 131-144

Probert, P. K. (1984). Disturbance, sediment stability, and trophic structure of soft-bottom communities. J. mar. Res. 42: 893-921

Sanders, H. L., Grassle, J. F., Hampson, G. R., Morse, L. S., Garner-Price, S., Jones, C. C. (1980). Anatomy of an oil spill: long-term effects from the grounding of the barge Florida off West Falmouth, Massachusetts. J. mar. Res. 38: $265-380$

Santos, S. L., Bloom, S. A. (1983). Evaluation of succession in an estuarine macrobenthic soft-bottom community near Tampala, Florida. Int. Revue ges. Hydrobiol. 68: $617-632$

Santos, S. L., Simon, J. L. (1980a). Response of soft-bottom benthos to annual catastrophic disturbance in a South Florida Estuary. Mar Ecol. Prog. Ser. 3: 347-355

Santos, S. L., Simon, J. L. (1980b). Marine soft-bottom community establishment following annual defaunation: larval or adult recruitment. Mar. Ecol. Prog. Ser. 2: 235-241

This article was submitted to the editor
Shannon, C. E., Weaver, W. (1963). The mathematical theory of communication. University of Illinois Press, Urbana, Illinois

Simberloff, D. S. (1969). Experimental zoogeography of islands: a model for insular colonization. Ecology 50: 296-314

Smith, C. R. (1986). Nekton falls, low-intensity disturbance and community structure of infaunal benthos in the deep sea. J. mar. Res. 44: 567-600

Spies, R. B., Davis, P. H. (1979). The infauna of a natural oil seep in the Santa Barbara Channel. Mar. Biol. 50: 227-237

Spies, R. B., Hardin, D. D., Toal, J. P. (1988). Organic enrichment or toxicity? A comparison of the effects of kelp and crude oil in sediments on the colonization and growth of benthic infauna. J. exp. mar. Biol. Ecol. 124: 261-282

Thistle, D. (1981). Natural physical disturbances and communities of marine soft bottoms. Mar. Ecol. Prog. Ser. 6 : 223-228

Warwick, R. M. (1986). A new method for detecting pollution effects on marine macrobenthic communities. Mar. Biol. 92: $557-562$

Westman, W. E. (1978). Measuring the inertia and resilience of ecosystems. BioScience 28: 705-710

Manuscript first received: September 18, 1989

Revised version accepted: June 26, 1990 